Originally published as:

Specke, V., Plesker, R., Wood, J., Coulibaly, C., Suling, K., Patience, C., Kurth, R., Schuurman, H.-J., Denner, J.

No in vivo infection of triple immunosuppressed non-human primates after inoculation with high titers of porcine endogenous retroviruses

(2009) Xenotransplantation, 16 (1), pp. 34-44.

DOI: 10.1111/j.1399-3089.2009.00508.x

The definitive version is available at www3.interscience.wiley.com 


\title{
No in vivo infection of triple immunosuppressed non- human primates after inoculation with high titers of porcine endogenous retroviruses*
}

\author{
Volker Specke, ${ }^{1,2}$ Roland Plesker, ${ }^{3}$ James Wood, ${ }^{4,5}$ Cheick Coulibaly, ${ }^{3}$ Kristen Suling, ${ }^{4,5}$ Clive \\ Patience, ${ }^{4,5}$ Reinhard Kurth, ${ }^{1}$ Henk-Jan Schuurman ${ }^{4,6}$ and Joachim Denner ${ }^{1}$ \\ ${ }^{1}$ Robert Koch-Institute, Berlin \\ 2 SKM Oncology Research, Wiesbaden \\ 3 Paul-Ehrlich-Institute, Langen, Germany, \\ ${ }^{4}$ Immerge BioTherapeutics, Inc., Boston, MA, \\ ${ }^{5}$ Biogen Idec, Cambridge, MA \\ ${ }^{6}$ Spring Point Project, Minneapolis, MN, USA
}

Background: Porcine endogenous retroviruses (PERVs) released from pig tissue can infect selected human cells in vitro and therefore represent a safety risk for xenotransplantation using pig cells, tissues, or organs. Although PERVs infect cells of numerous species in vitro, attempts to establish reliable animal models failed until now. Absence of PERV transmission has been shown in first experimental and clinical xenotransplantations; however, these trials suffered from the absence of long-term exposure (transplant survival) and profound immunosuppression.

Methods: We conducted infectivity studies in rhesus monkeys, pig-tailed monkeys, and baboons under chronic immunosuppression with cyclosporine $A$, methylprednisolone, and the rapamycin derivative. These species were selected because they are close to the human species and PERVs can be transmitted in vitro to cells of these species. In addition, the animals received twice, a C1 esterase inhibitor to block complement activation before inoculation of PERV. In order to overcome the complications of microchimerism, animals were inoculated with high titers of cell-free PERV. In addition, to enable transmission via cell-cell contact, some animals also received virus-producing cells. For inoculation the primate cell-adapted strain PERV/5_ was used which is characterized by a high infectious titer. Produced on human cells, this virus does not express alpha 1,3 Gal epitopes, does not contain porcine antigens on the viral surface and is therefore less immunogenic in nonhuman primates compared with pig cell-derived virus. Finally, we present evidence that PERV/5_ productively infects cells from baboons and rhesus monkeys.

Results: In a follow-up period of 11 months, no antibody production against PERV and no integration of proviral DNA in blood cells was observed. Furthermore, no PERV sequences were detected in the DNA of different organs taken after necropsy.

Conclusion: These results indicate that in a primate model, in the presence of chronic immunosuppression, neither the inoculation of cellfree nor cell-associated PERV using a virus already adapted to primate cells results in an infection; this is despite the fact that peripheral blood mononuclear cells of the same animals are infectible in vitro. 


\section{Introduction}

The widening gap between patients waiting for transplantation because of the ever increasing shortage of human donor organs have to be bridged by modern, innovative approaches in transplantation medicine. Xenotransplantation, the transplantation of living cells, tissues, or organs across species, is among the most promising approaches. However, xenotransplantation is associated with immunological rejection and/or physiological incompatibility of the xenotransplant as well as with the potential xenogenic transmission of micro-organisms [1-4]. It is anticipated that these problems can be solved by the use of genetically modified pigs $[5,6]$ and the generation of more effective immunsuppressive regimens.

While most pathogens can be eliminated by specified pathogen-free breeding, this derivation technology is not expected to affect the potential transmission of porcine endogenous retroviruses (PERV) as they are an integral part of all pig genomes. Generally, trans-species transmissions occur in nature and result either in immunodeficiencies (e.g., human immunodeficiency viruses: HIV-1 and HIV-2) and/or tumors (e.g., feline leukemia virus, FeLV; Koala retrovirus, KoRV) [7]. Although PERVs are able to infect several human cell types in vitro [8-12], the potential to infect humans in vivo and possibility to cause diseases remains to be established. Exploratory clinical xenotransplantation trials including ex vivo perfusion allowing short-term contact of human recipients to living porcine cells or tissues have not resulted in transmission of PERV [13-21]. Similarly, investigations of non-human primates that had received porcine cells or organs showed no

evidence of PERV infection [22-27]. Although PERV transmission was not investigated in more recent preclinical experiments with the longest ever survival time of xenotransplants, no signs of a retroviral disease were reported [28-30].

In an effort to establish an animal model most closely to man, three non-human primate species, rhesus monkeys, pig-tailed monkeys, and baboons under clinically relevant immunosuppression were inoculated with high titers of PERV. Two routes of virus administration were studied, namely, inoculation of cell-free virus and of cell-associated virus. During 11 month follow-up we assessed antibody production and the presence of PERV mRNA in the plasma. Furthermore, no PERV proviral sequences were detected in the DNA of blood cells or in the DNA of different organs taken after necropsy. Despite chronic, clinically relevant immunosuppression we were unable to document in vivo infection after inoculation of cell-free PERV or cell-associated PERV, while primary cells of the same animals were infectible in vitro.

\section{Materials and methods}

\section{Virus}

Either cell-free virus containing supernatant of PERV/5_-producing 293 cells or virus-producing cells were used. PERV/5_ was derived from PERVNIH/3 3 which is a recombinant PERV-A/C with PERV-A tropism (kindly provided by C. Wilson, FDA, WashingtonDC,USA[31])byserialpassaging on uninfected 293 cells. PERV/5 is characterized by very high virus titers and genetic alterations in the long terminal repeat region [32]. PERV-producing 293 cells or PK-15 cells were used as described [32].

\section{Virus titration}

Virus-containing supernatant produced by 1 - 107 PERV/5_-infected 293 cells was taken 3 days after the last medium change, and subsequently serially diluted in eight replicas, transferred to a 96-well plate with $3 \cdot 104 /$ well uninfected 293 cells, and incubated for $24 \mathrm{~h}$ at 37 C. On the following day, the supernatant was removed and the cells were washed and cultured for 4 weeks, splitting the cells every 3 to 4 days. To assess infection, a fraction of the cells was transferred to a poly-d-lysine-coated 96well plate on a weekly basis and washed twice with phosphate-buffered saline followed by fixation with methanol overnight at $) 20 \_C$ and assessment of recombinant p15E of PERV using an immunoperoxidase method described previously [33]. 


\section{In vitro infection}

Ten millilitre of virus-containing supernatant produced during a 3 day culture of 1 . 107 PERV/5_producing 293 cells (titer $1 \cdot 107 \mathrm{TCID50} / \mathrm{ml}$ ) (tissue culture infectious doses), PERV-A and -B producing 293 cells (titer $1 \cdot 103.2 \mathrm{TCID50} / \mathrm{ml}$ ), and PK-15 cells (titer 102.3 TCID50/ml) were added cell-free to $5 \cdot 106$ peripheral blood mononuclear cells (PBMCs) of rhesus monkeys, pig-tailed monkeys, and baboons cultured in 10 ml RPMI 1640 (Invitrogen, Karlsruhe, Germany), respectively, and incubated for $24 \mathrm{~h}$ at 37 _C. After the incubation, the supernatant was removed; cells were washed twice, and recultured in $20 \mathrm{ml}$ fresh medium for 10 days. Integration of PERV proviral DNA into the genome of infected cells was demonstrated by PCR using primers specific for PERV pol, gag, and env. Productive infection was shown by reverse transcriptase (RT) activity in the supernatant as well as by amplification of viral RNA isolated from pelleted virions via RT-PCR.

\section{Animals}

Rhesus monkeys (Macaca mulatta; \#178: male, $10 \mathrm{yr}$ old, $10.4 \mathrm{~kg}$ weight; \#179: male, $11 \mathrm{yr}$ old, 9.5 $\mathrm{kg}$ weight; \#180: male, $12 \mathrm{yr}$ old, $11 \mathrm{~kg}$ weight), pig-tailed monkeys (Macaca nemestrina; \# 6506: male, adult, $13.7 \mathrm{~kg}$ weight; \# 6501 male, $8 \mathrm{yr}$ old, $11 \mathrm{~kg}$ weight), and baboons (Papio hamadryas; \#6614: female, 8 yr old, $11.8 \mathrm{~kg}$ weight; \#7341: female, $7 \mathrm{yr}$ old, $11.6 \mathrm{~kg}$ weight) were used. Animals were housed at the Paul-Ehrlich Institute, Langen, Germany, and experiments were performed according the German animal welfare and husbandry laws.

\section{Immunosuppression}

All animals received daily an intramuscular injection of $10 \mathrm{mg} / \mathrm{kg}$ cyclosporine A (Cs-A, Sandimmune; Novartis Pharma AG, Basel, Switzerland) and $0.8 \mathrm{mg} / \mathrm{kg}$ of methylprednisolone acetate (Depo-Merol; Upjohn, Kalamazoo, MI, USA), and a subcutaneous injection of $0.075 \mathrm{mg} / \mathrm{kg}$ RAD (Novartis Pharma $A G$ ). The dose levels of these drugs were selected based on exploratory tolerability/ pharmacokinetic studies associated with efficacy in transplantation studies [34-36]. Injection of Cs-A was started 5 or 10 days before PERV inoculation (Fig. 1). Fifteen $\mathrm{mg} / \mathrm{kg}$ methylprednisolone sodium succinate (SoluMedrol; Upjohn) was given intravenously on the day of virus inoculation. Five hundred units of the Complement component (C1)-esterase inhibitor Berinert_HS (Aventis Behring, Marburg, Germany) were injected intravenously 3 days before and on the day of the second virus inoculation. This inhibitor was used because gamma retroviruses can be lysed directly by interaction of complement with the transmembrane envelope protein p15E [37].

\section{PERV inoculation schedule}

The animals were inoculated three times (days 0, 270, and 284) (Fig. 1, Table 1). Cell-free PERV/5 (titer 1. $107 \mathrm{TCID50} / \mathrm{ml}$ ) and PERV/5_-producing 293 cells (titer of their supernatant $1 \cdot \overline{1} 07$ TCID50/ml) were inoculated. Rhesus monkey \#179 died on day 14 due to bacterial septicemia presumably related to overimmunosuppression.

\section{Blood sample collection}

Before virus inoculation and every week thereafter, heparinized blood was taken for immunological testing and DNA isolation. In parallel, EDTA blood was taken for measuring the level of Cs-A, methylprednisolone, and RAD.

\section{Drug exposure}

Concentrations of methylpredisolone were measured by high-performance liquid chromatography at the Institute of Toxicological Chemistry, Humboldt University, Berlin, Germany (limit of detection: 10 $\mathrm{ng} / \mathrm{ml}$ ). Concentrations of Cs-A were measured using a EMIT 2000_ detection assay (Syva Company, Cupertino, CA, USA) at the Department of Nephrological Surgery, University Hospital, Frankfurt, Germany (limit of detection: $20 \mathrm{ng} / \mathrm{ml}$ ). Concentrations of RAD were measured using liquid chromatography/mass spectrometry at Drug Metabolism and Pharmacokinetics (Novartis Pharma AG; 
limit of detection: $2 \mathrm{ng} / \mathrm{ml}$ ). Concentrations of Berinert_HS C1-esterase inhibitor were measured using a Berichrom_C1 inhibitor detection assay (Dade Behring, Siemens Healthcare Diagnostics, Deerfield, IL, USA).

\section{DNA isolation}

DNA from PBMCs was isolated using preparation kits from Qiagen GmbH (Hilden, Germany). After necropsy, spleen, kidneys, heart, lung, liver, and lymph nodes were taken and stored at ) 80 _C. Organs were divided and analyzed independently at the Robert Koch Institute (Berlin, Germany) and Immerge BioTherapeutics (Boston, MA, USA). DNA was isolated using either standard phenol/ chloroform techniques (Robert Koch Institute) or QIAamp kits (Qiagen; Immerge BioTherapeutics) in accordance with the manufacturer's instructions.

\section{PCR}

This method was performed at the Robert Koch Institute. For the detection of provirus, primers specific for the pol [38] the gag [13], and the env gene of PERV-A [39] were used (Table 2). To control the quality of DNA, primers specific for the human b-actin gene (Clonetech, Mountain View, CA, USA) or for the baboon endogenous virus (BaEV) [40] were used. To identify human 293 cells, primers specific for adenovirus 5 (Ad5) sequences [41] were used. For amplification the standard PCR program ([95 _C, $10 \mathrm{~min}$ ] 1, [95_C, $1 \mathrm{~min}, 55$ _C, $1 \mathrm{~min}, 72$ _C, $1 \mathrm{~min}$ ] 35, [72_C, $7 \mathrm{~min}$ ] 1) was applied. To analyze the sensitivity of the PCR, $\overline{1} \cdot 106$ uninfected 293 cells were seeded in each well of a 96-well plate and were mixed with PERV/5_-producing 293 cells which were serially diluted in eight replicates from 2.104 to 1 cell. After cells were lyzed for $3 \mathrm{~h}$ at 56 _C in a lysis reagent containing $20 \mathrm{mg} / \mathrm{ml}$ proteinase K (Life Technologies, Eggenstein-Leopoldshafen, Germany) and PCR buffer ( $50 \mathrm{~mm} \mathrm{KCl}$; $1.5 \mathrm{~mm} \mathrm{MgCl2}$; $10 \mathrm{~mm}$ Tris-HCl; pH 8.4; Applied Biosystems, Foster City, CA, USA), enzyme was subsequently inactivated by incubation at 95 _C for $10 \mathrm{~min}$. Five II of this crude extract were used as template in a nested PCR using primers specific for PERV pol. One single PERV-producing cell was detected on the background of $1 \cdot 106$ uninfected 293 cells.

\section{Real time PCR}

This method was performed at Immerge BioTherapeutics using primers and probes for the swine leukocyte antigen (SLA) and PERV pol (Table 2). Real-time quantitative PCR was performed on 100 ng of DNA in a 25 II reaction mix (QuantiTect Probe PCR Kit, Qiagen) containing 12.5 Imoles of sense and antisense primers. The reactions were cycled at 50 _C for $2 \mathrm{~min}, 95$ C $10 \mathrm{~min}$, followed by 40 cycles of 95 _C 15 s, 60 _C 60 s. All reactions were quantified against known copy number plasmid controls. The sensitivities for both the SLA and PERV pol are quantitative at 10 copies.

\section{Nested PCR}

To increase the sensitivity, nested PCR was perfomed using internal and external pol primers (Table 2).

\section{$R T-P C R$}

Viral RNA from plasma of the inoculated animals was isolated using the high pure viral RNA isolation kit (Roche Diagnostic GmbH, Mannheim, Germany). RNA was reverse transcribed using an one-step RT-PCR kit (Life Technologies $\mathrm{GmbH}$ ) and cDNA was screened for PERV using PCR carried out with PERV-specific primers as described above (Table 2). 


\section{Western blot assays}

Western blots were performed as described [17] using PERV concentrated by ultracentrifugation, purified by sucrose gradient centrifugation, and subjected to denaturing $10 \%$ sodium dodecyl sulfatepolyacrylamide gel electrophoresis in tricine buffer. Proteins were transferred to polyvinylidene difluoride membranes by electroblotting. Membranes were blocked using $0.1 \%$ Tween 20 and $1 \%$ bovine serum albumin in Tris-buffered saline. Sera were incubated for $12 \mathrm{~h}$ at $4 \mathrm{C}$ and peroxidasecoupled species-specific anti-IgG antiserum for $2 \mathrm{~h}$ at room temperature. Antibody binding was visualized using metal-enhanced diaminobenzidine (Pierce, Rockford, IL, USA) and hydrogen peroxide. As positive control, a goat serum against recombinant p15E, goat serum against p27 of FeLV

cross-reacting with p27 of PERV, and a rabbit antiserum against purified PERV were used $[17,20]$.

\section{Measurement of RT}

Reverse transcriptase activity was measured in supernatants of overnight cultures of PERV/5_producing 293 cells, PERV-A and -B producing 293 cells, and PERV-producing PK-15 cells as well as in serum of rhesus monkeys and baboons by using a commercial assay (Cavidi Tech, Uppsala, Sweden).

\section{Enzyme-linked immuno assay}

Enzyme-linked immunoassays were performed as described[17]using96-wellplatescoatedwith0.2 lg/ well of recombinant p15E or of recombinant Gag of PERV,respectively. Plates were blocked with 100 II/ well 3\% bovine serum albumin (Serva, Heidelberg, Germany) in phosphate-buffered saline. Sera were diluted $1: 100$ in blocking solution and $100 \mathrm{l} /$ well were incubated for $1 \mathrm{~h}$ at 37 C. Horseradish peroxidaselabelledproteinGorhumanantilgGsecondary antibodies (Sigma, St. Louis, MO, USA), respectively, were diluted $1: 2000$ and $100 \mathrm{ll} /$ well were incubated for $1 \mathrm{~h}$ at room temperature. Antibody binding was visualized by adding 100 Il/well o-phenylenediamine dihydrochloride (Sigma).

\section{Results}

\section{Validation of model and methods}

The outcome of an in vivo infection study in adult immunosuppressed animals is mainly determined by three different parameters: (i) the titer of the inoculated virus; (ii) the susceptibility of the inoculated animal to infection; and (iii) the exposure to immunosuppressants at pharmacologically efficacious levels. We analyzed each of these parameters in detail.

The infectious potential of the PERV/5_ virus

stock used for inoculation was analyzed by titration of the virus by end point dilution on human 293 cells. The infectious titer of PERV/5_was estimated as $1 \cdot 107$ TCID50/ml after 4 weeks of cultivation.

We confirmed our previous data [41] that primary cells of rhesus monkeys and baboons and PBMCs of the animals used in this study were susceptible to infection with PERV/5_ (Fig. 2, Table 3). In kinetic studies as well as by measuring RT activity in the supernatant of infected PBMCs of rhesus monkeys and baboons and viral RNA in pelleted virions as measured by RT-PCR amplification, a productive infection in the sense of released virus particles was observed, whereas in the case of pig-tailed monkeys only provirus integration but no release of virus particles was observed [42] (Tables 4, 5). Similar results were reported by others [43]. It is important to underline that infection was only observed with high titer viruses, i.e., PERV/5_ and 293 cell-derived virus, but not with PERV released from PK-15 cells (Table 4). Immunological assays such as ELISA or western blot analysis were performed as indirect measures to detect a PERV infection assuming that an immunological response might be induced even under conditions of immunosuppression at pharmacologically active dose levels. The sensitivity of the ELISA was determined by end-point dilution of an anti-p15E serum using plates coated with $1 \mathrm{lg} /$ well recombinant p15E of PERV in which it was reached at $1: 1000000$. The 
sensitivity of the western blot analysis using $10 \mathrm{lg} / \mathrm{slot}$ purified PERV proteins was $1: 1000$ using the same antip15E serum, the sensitivity of the other western blot analyses were similar.

To analyze integration of proviral DNA into the genome of the animals, DNA from blood cells taken every 7 days and DNA isolated from different organs taken after necropsy was analyzed; this was carried out simultaneously by conventional PCR at the Robert Koch Institute and by real time PCR at Immerge Biotherapeutics. The sensitivity of the PCR method was one PERV/5_-producing 293 cell on a background of 1.106 uninfected 293 cells, and the sensitivities in the real time PCR for both the SLA and PERV pol were quantitative at 10 copies. The exposure to immunosuppressants was monitored weekly. In all animals the levels of Cs-A, methylprednisolone, and RAD were in the range of generally tolerable but strong immunosuppression (Table 3) [34-36,44-46].

\section{Evaluation during the in vivo study}

In order to develop a large animal model system for studies on viral safety that closely resembles the clinical situation, three species of non-human primates, namely, baboons, rhesus monkeys, and pigtailed monkeys, were inoculated with cell-free PERV/5_, a virus characterized by high titres [32]. All animals were inoculated with cell-free PERV/5_ both via the intraperitoneal and intravenous route and the follow-up was 260 days. During this follow-up, none of the animals showed antibodies to PERV. In addition, plasma was screened for PERV RNA by RT-PCR and for RT activity, also with negative results (data not shown). Furthermore, there was no integration of proviral DNA in the cellular DNA of blood cells observed in any of the animals using nested PCR with primers specific for gag, pol, and env (Fig. 3A). These data indicate that no infection and replication had taken place.

Because none of the animals showed any indication of PERV infection, a second inoculation was carried out on day 270 . The virus dose was trebled and the virus was inoculated intraperitoneally and intravenously, and in addition also subcutaneously and intramuscularly. Furthermore, a C1-esterase inhibitor was given to inhibit potential complement activation. To study virus transmission via cell-cell contact, rhesus monkey \#180 and baboon \#7341 received in addition 1 . 109 PERV/5_-producing 293 cells. To further increase virus exposure, the animals were inoculated again 14 days later on day 284 , at that time without concomitant C1-esterase treatment.

During follow-up after these inoculations, none of the animals showed either integration of PERV/ 5 proviral DNA in genomic DNA of blood cells (Fig. 3B) or production of antibodies (Fig. 3C). In some animals, antibodies to bovine serum albumin, a component of the virus containing supernatant, was observed indicating that despite chronic immunosuppression, antibodies against other antigens were induced (data not illustrated).

\section{Postmortem evaluation}

Rhesus monkey \#179 died on day 14 after the first inoculation due to bacterial infection probably related to over-immunosuppression. The other animals were euthanized on day 46 (rhesus monkey \#180), on day 316 (rhesus monkey \#178), and on day 336 (baboons \#6614 and \#7341), respectively. Organs were divided and analyzed independently at the Robert Koch Institute and Immerge Bio-

Therapeutics. DNA was isolated from blood, heart, aorta, lymph nodes, liver, lung, kidneys, and spleen, and screened for PERV/5_ proviral DNA using conventional PCR (Robert Koch Institute) and real-time PCR (Immerge BioTherapeutics). In none of the samples, amplicons of sequences specific for PERV gag, pol, or env could be detected (data not illustrated).

Rhesus monkey \#180 developed tumors at several locations including multiple sites in the peritoneum as well as in the muscles of chest and legs, in particular at the sites of inoculation of virus-producing cells. The presence of tumor cells

was associated with the presence of the transforming E1 region of Ad 5 in the DNA, indicating that the tumor cells originated from the 293 kidney cells inoculated. Using primers specific for the E1 region of Ad 5, 293 cells were found in all tumors (Fig. 4). A similar development of tumors has been observed after inoculating 293 cells into immunodeprived nude mice [47]. Therefore it is likely that the development of the tumors was not due to viral infection with PERV/5_ but due to the tumorigenic potential of the inoculated 293 cells in this animal. 


\section{Discussion}

There is a clear need for a reliable animal model to evaluate the potential risk of PERV transmission associated with xenotransplantation. Following the documentation that PERV can be transmitted in vitro to primary cells from rhesus monkeys and baboons using high titers of PERV/5_ [42] (Tables 4 , 5), the present study was intended to evaluate the potential risk of PERV transmission to non-human primates in vivo. In contrast to in vivo studies using grafts of porcine cells or organs into non-human primates [22-30], the present study simulated a "worst case scenario" of virus release. This experimental setting was chosen to bypass shortcomings of exploratory clinical trials [13-21]: (i) the short survival and function of xenografts; (ii) the small numbers of porcine cells or material other than solid organs transplanted [13,16,18-20]; (iii) the encapsulation of cellular xenotransplants in some studies [13,19,21]; (iv) the short exposure time and small area of contact in studies using extracorporeal perfusion of blood [13-16,20]; and (v) insufficient immunosuppression resulting in short survival. We therefore embarked on a protocol in which animals were chronically immunosuppressed by Cs-A, methylprednisolone, and RAD at pharmacologically relevant dose levels, and were inoculated at two time points at multiple locations with very high titers (1 109 to $3 \cdot 109$ TCID50) of PERV, and subsequently subjected to an 11-month follow-up. The virus used, PERV/5_, infected in vitro non-human primate cells more efficiently than others viruses (Table 4). In contrast to pig cellderived virus, PERV/5_ produced in human 293 cells does not carry alpha 1,3 Gal epitopes [48] and no pig membrane proteins in the viral envelope [49] and is therefore in non-human primates less susceptible to the innate and adaptive immune responses. We used the most sensitive assays to detect PERV integration in the DNA of PBMCs and various tissues (PCR, nested PCR, and real time PCR), and applied indirect immunological testing such as western blot (Fig. 3C), ELISAs, and RT assays. To our knowledge, there are no reports in the literature showing provirus integration in cells in the absence of an antibody response at later time points after infection with various retroviruses.

All animals in the present study showed susceptibility to PERV infection in in vitro infection of primary cells (Fig. 2, Tables 4,5). The baboons and rhesus monkeys manifested a productive infection as demonstrated by increased RT activity in the supernatant and viral genomic RNA in the pelleted viruses but pig-tailed monkeys only demonstrated integrated proviral DNA and no release of virus particles [42] (Table 4). It remains to be determined whether the presence of PERV provirus in cells from pig-tailed monkeys indicates an infection with provirus integration or an uptake of viral DNA. This aside, it remains possible that certain cell types not tested in vitro may be infected in the organism of pig-tailed monkeys. Ritzhaupt et al. [43] showed that cell lines from African green monkey, rhesus macaque, and baboon were infected with PERV as measured by viral DNA and RNA using PCR and RT-PCR assays. Virions released from these infected cells could productively infect naive human cell lines confirming our data. We have also shown productive infection of rhesus kidney cells and lymphoid cells from chimpanzees (Irgang M, Denner J, unpublished). The fact that PERV does not replicate well in primate cells including most human cells suggests that intracellular restriction factor such as tripartite motif-a and apolipoprotein B mRNA editing enzyme, catalytic polypeptide-like (APOBEC) may inhibit virus replication (for review, see $[50,51]$ ). These factors may be neutralized by higher virus doses, enabling high titer viruses such as PERV/5_ to achieve productive infection. We therefore conclude that there is no need to re-evaluate the appropriateness of non-human primates as suitable animal models. In contrary, in our experience it is difficult to reach a productive infection in most human primary cells and cell lines with exception of 293 kidney cells (which were transformed by Ad5 and do not express APOBEC). In contrast to PERVs released by primary pig cells and by pig cell lines, the PERV/5_ used in this study is characterized by very high infectious titers ( $1 \cdot 107 \mathrm{TCID} 50 / \mathrm{ml})$ [32,52]. This enhanced replication potential is due to multiple transcription factor (TF) binding sites for the nuclear TF nuclear factor-Y (NF-Y). We used high doses of this virus to inoculate the animals and to simulate a situation of a massive release of PERV from an implanted porcine xenotransplant. Even mimicking this "worst-case" scenario, none of the animals showed any evidence of infection during a follow up to 11 months (Fig. 3). This result is remarkable in view of (i) transmission of PERV in vitro to cells of the same animals; (ii) the profound chronic immunosuppression at pharmacologically efficacious dose levels; (iii) multiple application of cell-free high-titer PERV; (iv) the use of cellassociated virus in addition to cell-free virus in some animals; ( $v$ ) various sites and administration routes of virus, and (vi) the long-term follow-up period. One explanation of the difference between the in vitro and in vivo data might be the efficient elimination of PERVs by the naturally existing immunity which is not affected by conventional immunosuppression. The complement system and pre-formed natural antibodies may be involved in this process [53-56]. Innate host defense mechanisms might explain the fact that the initial virus load in infectivity studies has to be much higher than that used in vitro infection [56]. In studies using guinea pigs and lambs a transient PERV transmission was observed after inoculation of virus or applying pig tissue [57,58]. This transient infection was observed in the first days after infection and declined later. Although in this study cells could not be collected in 
the first week after PERV inoculation, long-term infection (up to $1 \mathrm{yr}$ ) in the presence of immunosuppressant was found negative (Fig. 1-3). In order to avoid microchimerism, we applied cellfree virus and in order to allow cell-cell contact as part of the worst case scenario, we applied cells producing large quantities of human cell adapted virus. In contrast to virus released from implanted cell aggregates [59] this virus is characterized by a virus titer, absence of alpha 1,3 Gal epitopes and absence of pig antigens. Data on productive PERV transmission in vivo do not exist, and hence the situation in human xenotransplant recipients remains open for speculation. Literature documents indicate that PERV may not easily infect target individuals in vivo, i.e., first xenotransplantation patients [13-21] including liver failure patients receiving ex vivo perfusions using porcine hepatocytes [13-15,20] and butchers having often blood-blood contact with pigs [17]. This is underscored by pig to monkey transplantations [22-30], in vivo infection experiments with small animals (for review see [60]), and the infection experiments with non-human primates in the present study.

\section{Acknowledgments}

We thank Dr.C.Wilson, FDA,Bethesda,MD,USA, for kindly providing the uninfected293cells as well as the PERV/NIH/3_-producing 293 cells; U. Thiesen, RKI, Berlin, Germany for excellent technical assistance; Dr. I. Hauser, University Hospital Frankfurt/ Mainfor measurement of Cs-A; Drs. I. Leupi andM. Rouilly, Novartis Pharma AG, Basel, Switzerland, for measurement of RAD; Prof. Dr. F. Pragst, Charite, Berlin, Germany, for measurement of methylprednisolone; Dr. G. Langford, Imutran Ltd (A Novartis Pharma AG Company), Cambridge, UK, for her advice regarding PERV infectivity. This work was partially supported by the German Ministry of Health.

\section{References}

1. Boneva RS, Folks TM, Chapman LE. Infectious disease issues in xenotransplantation. Clin Microbiol Rev 2001; 14: 1.

2. Onions D, Cooper DK, Alexander TJ et al. An approach to the control of disease transmission in pigto- human xenotransplantation. Xenotransplantation 2000; 7: 143.

3. Denner J. Immunosuppression by retroviruses: implications for xenotransplantation. Ann N Y Acad Sci 1998; 862: 75

4. Denner J. Is porcine endogenous retrovirus (PERV) transmission still relevant? Transplant Proc 2008; 40: 587- 589.

5. Dai Y, vaught TD, Boone J et al. Targeted disruption of the a1,3-galactosyltransferase gene in cloned pigs. Nat Biotech 2002; 20: 251.

6. Lai L, Kolber-Simonds D, Park KW et al. Production of alpha-1,3-galactosyltransferase knockout pigs by nuclear transfer cloning. Science 2002; 295: 1089.

7. Denner J. Transspecies transmissions of retroviruses: new cases. Virology 2007; 369: $229-233$.

8. Patience C, Takeuchi Y, Weiss RA. Infection of human cells by an endogenous retrovirus of pigs. Nat Med 1997; 3: 282.

9. Takeuchi Y, Patience C, Magre S et al. Host range and interference studies of three classes of pig endogenous retrovirus. J Virol 1998; 72: 9986.

10. Martin U, Winkler ME, Id $\mathrm{M}$ et al. Productive infection of primary human endothelial cells by pig endogenous retrovirus (PERV). Xenotransplantation 2000; 7: 138.

11. Wilson CA, Wong S, Muller J, Davidson CE, Rose TM, Burd P. Type C retrovirus released from porcine primary peripheral blood mononuclear cells infects human cells. J Virol 1998; 72: 3082

12. Specke V, Rubant S, Denner J. Productive infection of human primary cells and cell lines with porcine endogenous retroviruses. Virology 2001; 285: 177.

13. Paradis K, Langford G, Long Z et al. Search for crossspecies transmission of porcine endogenous retrovirus in patients treated with living pig tissue. Science 1999; 285: 1236.

14. Pitkin Z, Mullon C. Evidence of absence of porcine endogenous retrovirus (PERV) infection in patients treated with a bioartificial liver support system. Artif Organs 1999; 23: 829.

15. Levy MF, Crippin J, Sutton S et al. Liver allotransplantation after extracorporeal hepatic support with transgenic (hCD55/hCD59) porcine livers: clinical results and lack of pig-to-human transmission of the porcine endogenous retrovirus. Transplantation 2000; 69: 272-280.

16. Patience C, Patton GS, Takeuchi $Y$ et al. No evidence of pig DNA or retroviral infection in patients with shortterm extracorporeal connection to pig kidneys. Lancet 1998; 352: 699.

17. Tacke SJ, Bodusch K, Berg A, Denner J. Sensitive and specific immunological detection methods for porcine endogenous retroviruses applicable to experimental and clinical xenotransplantation. Xenotransplantation 2001; 8: 125.

18. Fink JS, Schumacher JM, Elias SL et al. Porcine xenografts in Parkinson's disease and Huntington's disease patients: preliminary results. Cell Transplant 2000; 9: 273.

19. Elliott RB, Escobar L, Garkavenko O et al. No evidence of infection with porcine endogenous retroviruse in recipients of encapsulated porcine islet xenografts. Cell Transplant 2000; 9: 895.

20. Irgang M, Sauer IM, Karlas A et al. Porcine endogenous retroviruses (PERVs): no infection in patients treated with a bioreactor based on porcine liver cells. J Clin Virol 2003; 28: 141-154.

21. Garkavenko O, Croxson MC, Irgang M, Karlas A, Denner J, Elliot RB. Monitoring for presence of potentially xenotic viruses in recipients of pig islet xenotransplantation. J Clin Microbiol 2004; 42: 5353-5356.

22. Martin U, Steinhoff G, Kiessig V et al. Porcine endogenous retrovirus (PERV) was not transmitted from porcine endothelial cells to baboons in vivo. Transplant Int 1998; 11: 247. 
23. Switzer WM, Michler RE, Shanmugam $V$ et al. Lack of cross-species transmission of porcine endogenous retrovirus infection to nonhuman primate recipients of porcine cells, tissues, or organs. Transplantation 2001; 71: 959.

24. Martin U, Tacke SJ, Simon AR et al. Absence of PERV specific humoral immune response in baboons after transplantation of porcine cells or organs. Transplant Int 2002; 15: 361.

25. Simon AR, Templin C, Schröder C et al. No evidence for productive PERV infection of baboon cells in in vivo infection model. Ann Transplant 2003; 8: 24-34.

26. Winkler ME, Winkler M, Burian $\mathrm{R}$ et al. Analysis of pig-to-human porcine endogenous retrovirus transmission in a triplespecies kidney xenotransplantation model. Transplant Int 2005; 17: 848-858.

27. Issa NC, Wilkinson RA, Griesemer A et al. Absence of replication of porcine endogenous retrovirus and porcine lymphotropic herpes virus type 1 with prolonged pig-cell microchimerism after pig-to-baboon xenotransplantation. J Virol 2008; 82: 12441-12448. (Epub 1 Oct 2008).

28. Kuwaki K, Tseng YL, Dor FJ et al. Heart transplantation in baboons using alpha1,3-galactosyltransferase geneknockout pigs as donors: initial experience. Nat Med 2005; 11: 29-31.

29. Hering BJ, Wijkstrom M, Graham ML et al. Prolonged diabetes reversal after intraportal xenotransplantation of wild-type porcine islets in immunosuppressed nonhuman primates. Nat Med 2006; 12: 301-303.

30. Cardona K, Korbutt GS, Milas Z et al. Long-term survival of neonatal porcine islets in nonhuman primates by targeting costimulation pathways. Nat Med 2006; 12: 304-306.

31. Wilson CA, Wong S, VanBrocklin M, Federspiel MJ. Extended analysis of the in vitro tropism of porcine endogenous retrovirus. J Virol 2000; 74: 49.

32. Denner J, Specke V, Thiesen U, Karlas A, Kurth R. Genetic alterations of the long terminal repeat of an ecotropic porcine endogenous retrovirus (PERV) during passage in human cells. Virology 2003; 314: 125-133.

33. Stephan O, Schwendemann J, Specke V, Tacke J, Boller K, Denner J. Porcine endogenous retroviruses (PERVs): generation of specific antibodies, development of an immunoperoxidase assay (IPA) and inhibition by AZT. Xenotransplantation 2001; 8: 310 .

34. Schuurman HJ, Cottens S, Fuchs $S$ et al. SDZ RAD, a new rapamycin derivative: synergism with cyclosporine. Transplantation 1997; 64: 32.

35. Schuurman HJ, Ringers J, Schuler W, Slingerland W, Jonker M. Oral efficacy of a macrolide immunosuppressant SDZ RAD and of cyclosporine microemulsion in cynomolgus monkey kidney allotransplantation. Transplantation 2000; 69: 737.

36. Minanov OP, Artrip JH, Szabolcs M et al. Triple immunosuppression reduces mononuclear cell infiltration and prolongs graft life in pig-to newborn baboon cardiac xenotransplantation. J Thorac Cardiovasc Surg 1998; 115: 998.

37. Bartholomew RM, Esser AF, Müller-Eberhard HJ. Lysis of oncornaviruses by human serum. Isolation of the viral complement (C1) receptor and identification as p15E. J Exp Med 1978; 147: 844-853.

38. Czauderna F, Fischer N, Boller K, Kurth R, Tönjes RR. Establishment and characterization of molecular clones of porcine endogenous retroviruses replicating on human cells. J Virol 2000; 74: 4028.

39. Le Tissier PI, Stoye JP, Takeuchi Y, Patience C, Weiss RA. Two sets of humantropic pig retrovirus. Nature 1997; $389: 681$.

40. Van der Kuyl AC, Dekker JT, Goudsmith J. Fulllength provirus of baboon endogenous retrovirus (BaEV) and dispersed BaEV reverse transcriptase retroelements in the genome of baboon species. J Virol 1995; 69: 5917.

41. Louis N, Evelegh C, Graham FL. Cloning and sequencing of the cellular viral junctions from the human adenovirus type 5 transformed 293 cell line. Virology 1997; 233: 423.

42. Specke V, Schuurman HJ, Plesker R et al. Virus safety in xenotransplantation: first exploratory in vivo studies in small laboratory animals and non-human primates. Transpl Immunol 2002; 9: 281.

43. Ritzhaupt A, Van Der Laan LJ, Salomon DR, Wilson CA. Porcine endogenous retrovirus infects but does not replicate in nonhuman primate primary cells and cell lines. J Virol 2002; 76: 11312.

44. Schuurman HJ, Slingerland W, Menninger K et al. Pharmakokinetics of cyclosporine in monkeys after oral and intramuscular administration: relation to efficacy in kidney allografting. Transplant Int 2001; 14: 320.

45. Bühler L, Goepfert C, Kitamura $\mathrm{H}$ et al. Porcine hematopoietic cell xenotransplantation in nonhuman primates is complicated by thrombotic microangiopathy. Bone Marrow Transplant 2001; 27: 1227.

46. Dareer SME,Struck RF, WhiteVM,Mellett LB, Hill DL. Distribution and metabolism of prednisolone in mice, dogs and monkeys. Cancer Treat Reports 1977; 61: 1279

47. Busuttil A, O'Conor GT, Foster ME, Gurtsevitch V, Morten JE, Steel CM. The gross pathology and histological features of tumours produced by inoculation of human cell lines into immunedeprived mice. J Pathol 1986; 148: 293.

48. Quinn G, Wood JC, Ryan DJ et al. Porcine endogenous retrovirus transmission characteristics of galactose alpha1- 3 galactose-deficient pig cells. J Virol 2004; 78: 5805-5811.

49. Arthur LO, Bess JW Jr, Sowder RC et al. Cellular proteins bound to immunodeficiency viruses: implications for pathogenesis and vaccines. Science 1992; 258: 1935- 1938.

50. Towers GJ. The control of viral infection by tripartite motif proteins and cyclophilin A. Retrovirology 2007; 4: 40.

51. Goila-Gaur R, Strebel K. HIV-1 Vif, APOBEC, and intrinsic immunity. Retrovirology 2008; 5: 51.

52. Denner J. Recombinant porcine endogenous retroviruses (PERV-A/C): a new risk for xenotransplantation? Arch Virol 2008; 153: 1421-1426.

53. Lachmann PJ, Davies A. Complement and immunity to viruses. Immunol Rev 1997; 159: 69.

54. Ochsenbein AF, Zinkernagel RM. Natural antibodies and the complement link innate and acquired immunity. Immunol Today 2000; 21: 624.

55. Alfano M, Poli G. Role of cytokines and chemokines in the regulation of innate immunity and HIV infection. Mol Immunol 2005; 42: 161-182.

56. Baron S, Singh I, Chopra A, Coppenhaver D, Pan J. Innate antiviral defences in body fluids and tissues. Antivir Res 2000; 48: 71

57. Popp SK, Mann DA, Milburn PJ et al. Transient transmission of porcine endogenous retrovirus to fetal lambs after pig islet tissue xenotransplantation. Immunol Cell Biol 2007; 85: 238-248.

58. Argaw T, Colon-Moran W, Wilson CA. Limited infection without evidence of replication by porcine endogenous retrovirus in guinea pigs. J Gen Virol 2004; 85: 15-19.

59. Simeonovic CJ, Ziolkowski AF, Popp SK et al. Porcine endogenous retrovirus encodes xenoantigens involved in porcine cellular xenograft rejection by mice. Transplantation 2005; 79: 1674-1682.

60. Louz D, Bergmans HE, Loos BP, Hoeben RC. Reappraisal of biosafety risks posed by PERVs in xenotransplantation. Rev Med Virol 2008; 18: 53-65. 


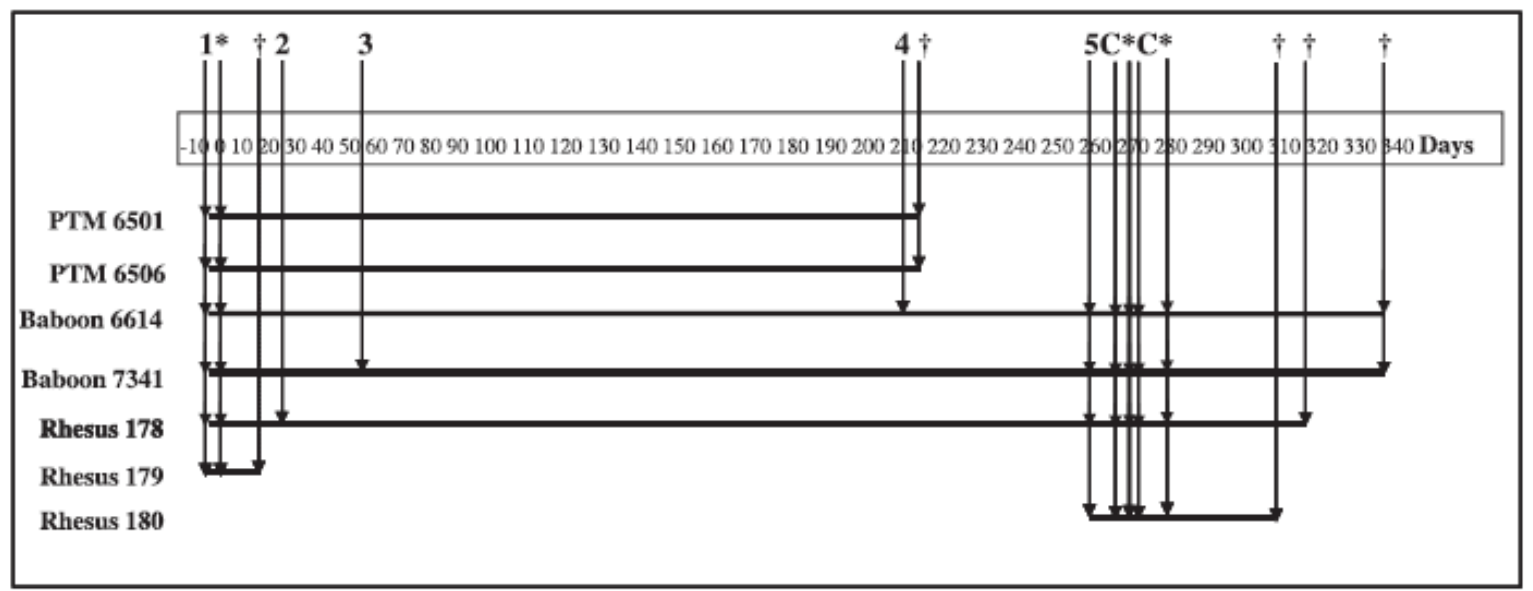

Fig. 1. Time schedule of the in vivo porcine endogenous retroviruses (PERV) inoculations: 1 , daily application of cyclosporine A started 5 days before first PERV inoculation; 2, stop of immunosuppression for rhesus monkey \#178; 3, stop of immunosuppressionfor baboon \#7341; 4, stop of immunosuppression for baboon \#6614; 5, start of immunosuppression 10 days before second PERV inoculations; C, application of C1 esterase inhibitor; *, inoculation of PERV; death/euthanasia.

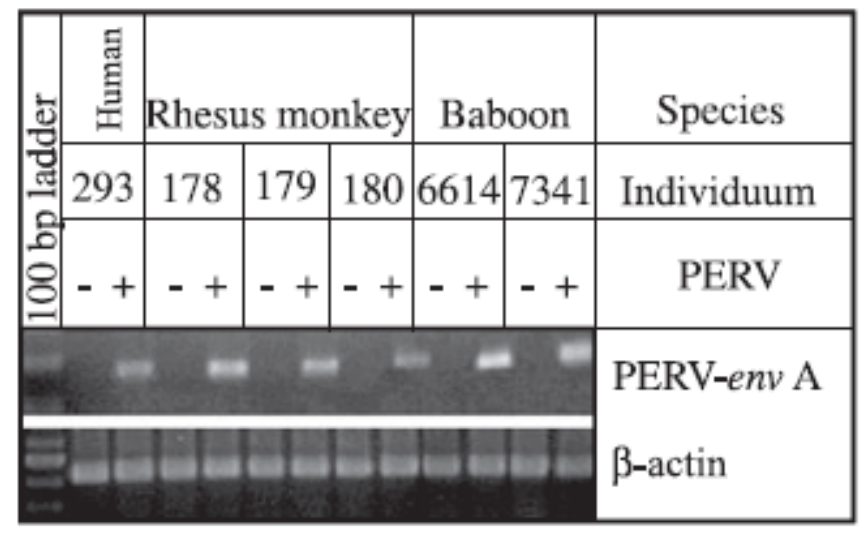

Fig. 2. In vitro infection of primary peripheral blood mononuclear cells (PBMCs) from rhesus monkeys and baboons used in the in vivo experiment. $5 \cdot 106$ PBMCs from rhesus monkeys and baboons were incubated for $24 \mathrm{~h}$ with $10 \mathrm{ml}$ of virus-containing supernatant of $1 \cdot 107$ porcine endogenous retroviruses (PERV)/5_-producing 293 cells (Titer $1 \cdot 107 \mathrm{TCID50} / \mathrm{ml}$; tissue culture infectious doses). DNA was isolated 10 days after inoculation and integration of proviral DNA was demonstrated by using PCR and primers specific for PERV-env A, uninfected ()), and infected (+) PBMCs. DNA from uninfected ()) and PERV/5_infected (+) 293 cells was used as negative and positive controls. Primers for b-actin were used to control loading of DNA. 
A)

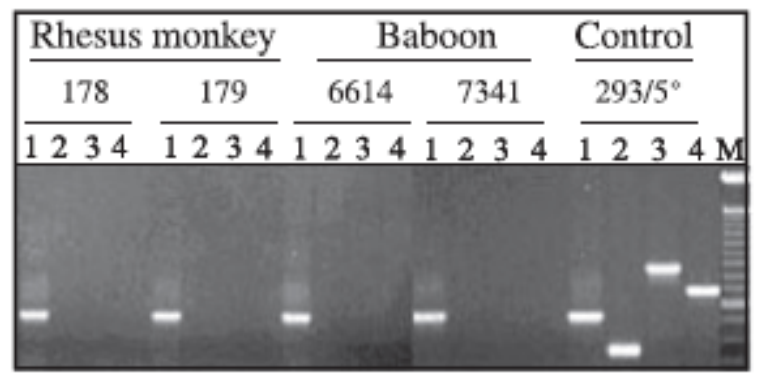

B)

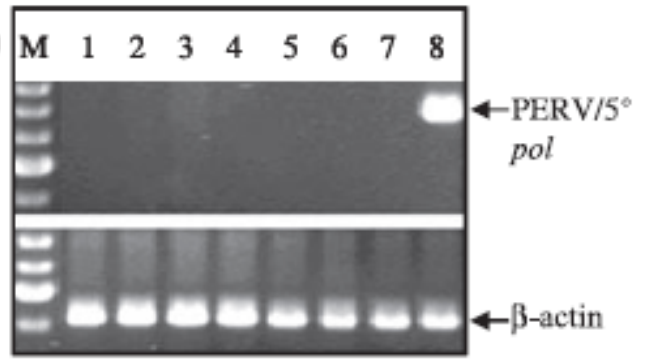

C)

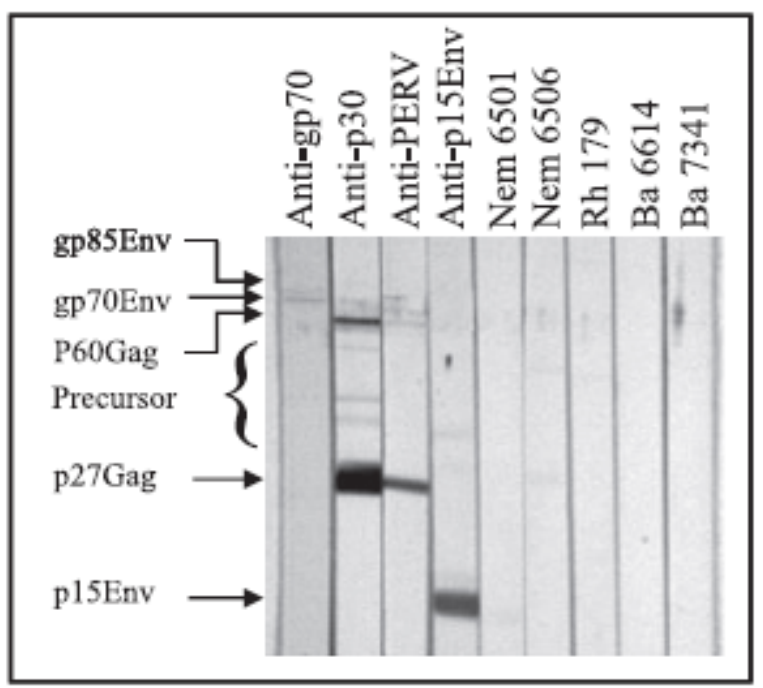

Fig. 3. PCR analysis and western blot analysis. (A) PCR analysis of peripheral blood mononuclear cells (PBMCs) taken

from rhesus monkeys and baboons 260 days after inoculation with porcine endogenous retroviruses (PERV)/5 in vivo and using primers specific for b-actin (1), for PERV envA (2), gag (3), and pol (4). DNA from PERV/5_infected 293 cells was

used as positive control. (B) Nested PCR with DNA from PBMCs taken at day 336 from rhesus monkey \#178 (1), rhesus monkey \#180 (2), baboon \#6614 (3), and baboon \#7341 (4) was performed using primers specific for the pol gene of PERV.

DNA from uninfected PBMCs of rhesus monkey \#180 (5), baboon \#6614 (6), and uninfected 293 cells (7) were used as negative control, DNA from PERV/5_-infected 293 cells was used as positive control (8). Primers for b-actin were used to control loading of DNA. (C) Western blot analysis of sera from inoculated non-human primates obtained 12 weeks postinoculation with PERV/5_(Nem-pig tailed monkey, Rh-rhesus monkey, Ba-baboon). To control the quality of the blot and the blotting procedure, animal sera against several structural proteins of PERV were included.

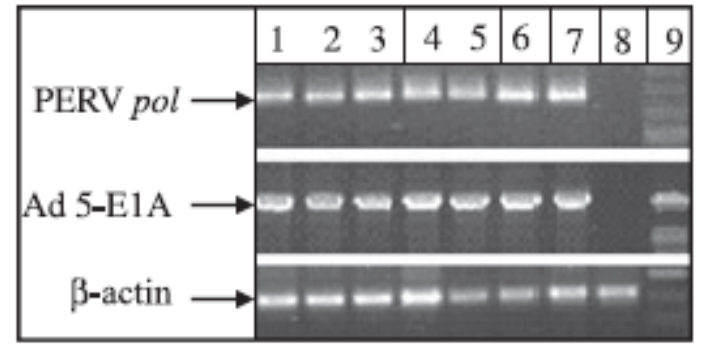

Fig. 4. PCR analysis of different tumors from rhesus monkey \#180. PCR was performed using primers specific for porcine endogenous retroviruses (PERV) pol. Presence of 293 cells in these tumors was shown by PCR using primers specific for E1 region of adenovirus 5 (Ad 5). 1-3: Tumors of the peritoneum; 4, 5: tumors of the pectoral muscles; 6 : tumor of the leg. DNA from PERV/5_infected 293 cells (7) and uninfected rhesus monkey peripheral blood mononuclear cells (8) were used as positive and negative control, primers for b-actin were used to control the loading of DNA, 9: $100 \mathrm{bp}$ ladder. 
Table 1. PERV inoculation schedule

\begin{tabular}{|c|c|c|c|c|c|c|c|c|c|c|c|c|}
\hline \multirow[b]{3}{*}{ Animal } & \multirow{2}{*}{\multicolumn{2}{|c|}{$\frac{\text { Day } 0}{\text { Virus (ml) }}$}} & \multicolumn{5}{|c|}{ Day $270^{2}$} & \multicolumn{5}{|c|}{ Day 284} \\
\hline & & & \multicolumn{4}{|c|}{ Virus (ml) } & \multirow[b]{2}{*}{ Cells $\left(\times 10^{8}\right)$} & \multicolumn{4}{|c|}{ Virus (ml) } & \multirow[b]{2}{*}{ Cells $\left(\times 10^{6}\right.$} \\
\hline & i.p. & i.v. & ip. & i.v. & s.c. & i.m. & & i.p. & i.v. & s.c. & i.m. & \\
\hline PIM 6501 & 50 & 50 & & & & & & & & & & \\
\hline PTM 6506 & 50 & 50 & & & & & & & & & & \\
\hline Baboon 6614 & 50 & 50 & 50 & 250 & $2 \times 5$ & $2 \times 1$ & & & & & & \\
\hline Baboon 7341 & 50 & 50 & 10 & 10 & $2 \times 5$ & $2 \times 1$ & 2,5 & 50 & 250 & $2 \times 5$ & $2 \times 1$ & 2,5 \\
\hline Rhesus 178 & 50 & 50 & 50 & 250 & $2 \times 5$ & $2 \times 1$ & & & & & & \\
\hline Rhesus 179 & 50 & 50 & & & & & & & & & & \\
\hline Phesus 180 & & & 10 & 10 & $2 \times 5$ & $2 \times 1$ & 2,5 & 50 & 250 & $2 \times 5$ & $2 \times 1$ & 2,5 \\
\hline
\end{tabular}

PERV, porcine endogenous retroviruses.

"Day 0 for Rhesus 180.

Table 2. Primers and probes used for the detection of PERV transmission in PCR, RT-PCR, real time PCR, and nested PCR assays

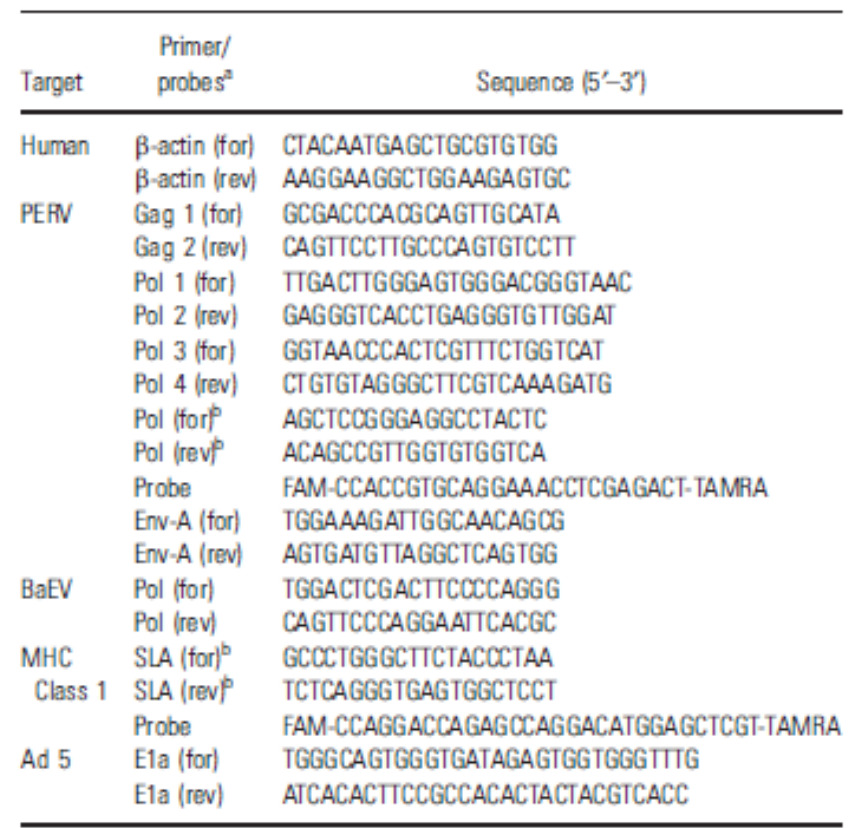

PERV, porcine endogenous retroviruses; SLA, swine leukocyte antigen; BaEV, baboon endogenous virus; MHC, major histocompatability complex; Ad, adenovirus; RT-PCR, reverse transcriptase polymerase chain reaction.

"for, forward primer, rev, reverse primer.

bPrimers for real time PCR. 
Table 3. Concentration of immunosuppressants in the plasma of rhesus monkeys and baboons receiving daily cyclosporin A, prednisolone, and RAD

\begin{tabular}{|c|c|c|c|c|c|c|}
\hline Immunosuppressant & 178 & 179 & 180 & 6614 & 7341 & $\begin{array}{c}\text { Tolerable effective } \\
\text { plasma dose } \\
\text { [references] }\end{array}$ \\
\hline Prednisolone [ng/ml] & $26.0 \pm 7$ & $27.0 \pm 5$ & $25.8 \pm 13.5$ & $30.0 \pm 14$ & $30.0 \pm 14$ & $20-60[45]$ \\
\hline RAD [ng/ml] & $9.4 \pm 4$ & $8.2 \pm 2.5$ & $7.0 \pm 3$ & $15.8 \pm 6.6$ & $7.3 \pm 4.7$ & $5-30[34,35]$ \\
\hline
\end{tabular}

RAD, rapamycin derivative.

Mean $\pm \mathrm{SD}$ of up to 48 samples. Dose levels were given in $\mathrm{ng} / \mathrm{ml}$. Tolerable plasma dose was taken from literature as cited in the table.

Table 4. In vitro infection of non-human primate primary cells with different PERVs

\begin{tabular}{|c|c|c|c|c|c|c|c|}
\hline Species & Tissue & Virus source & $\begin{array}{l}\text { Inoculated } \\
\text { virus, titer/ml }\end{array}$ & $\begin{array}{c}\text { PCR } \\
7 \text { days p.i. }\end{array}$ & $\begin{array}{c}\text { Rा-PCR } \\
7 \text { days p.i. }\end{array}$ & \multicolumn{2}{|c|}{ Released RT activity [mU/ml] } \\
\hline \multirow{2}{*}{ Phesus monkey } & \multirow{2}{*}{ PBMC } & PERV/293 & $1 \times 10^{32}$ & + & + & $11 \pm 1.5$ & n.t. \\
\hline & & PERN/PK & $1 \times 10^{23}$ & - & - & $0 \pm 0.2$ & $0 \pm 0.07$ \\
\hline \multirow[t]{5}{*}{ Baboon } & PBMC & $\mathrm{PERN} / 5^{\circ}$ & $1 \times 10^{7}$ & + & + & $14 \pm 3.0$ & n.t. \\
\hline & \multirow[t]{2}{*}{ Spleen } & PERV/293 & $1 \times 10^{32}$ & + & + & $0 \pm 0.7$ & $7 \pm 0.7$ \\
\hline & & PERN/PK & $1 \times 10^{23}$ & - & - & $0 \pm 0.2$ & $0 \pm 0.13$ \\
\hline & \multirow[t]{2}{*}{ Kidney } & PERV/293 & $1 \times 10^{32}$ & - & - & $0 \pm 0.5$ & $0 \pm 0.2$ \\
\hline & & PERN/PK & $1 \times 10^{23}$ & - & - & $0 \pm 0.12$ & $0 \pm 0.3$ \\
\hline \multirow[t]{2}{*}{ Pig-tailed monkey } & PBMC & $\mathrm{PERN} / 5^{\circ}$ & $1 \times 10^{7}$ & - & - & $0 \pm 0.03$ & $0 \pm 0.1$ \\
\hline & Spleen & & & + & - & $0 \pm 0.08$ & $0 \pm 0.08$ \\
\hline
\end{tabular}

PEAV, porcine endogenous retroviruses; PBMC, peripheral blood mononuclear cells; PK, pig kidney, p.i., post-infection.

Mean \pm SD of triplicate measurement.

Table 5. Spread of PERV infection in primary baboon cells inoculated in vitro

\begin{tabular}{lllllll}
\hline Tissue & \multicolumn{7}{c}{ RT activity $[\mathrm{mU} / \mathrm{m}$ ] } \\
\hline PBMCs & $280 \pm 6$ & $32 \pm 2.5$ & $0 \pm 0.3$ & $0 \pm 0.3$ & $9 \pm 0.3$ & $11 \pm 0.5$ \\
Spleen $^{a}$ & $280 \pm 6$ & $22 \pm 0.9$ & $0 \pm 0.7$ & $0 \pm 0.8$ & $6 \pm 0.4$ & $7 \pm 0.7$ \\
Provirus $^{a}$ & - & - & + & + & + & + \\
Viral ANA $^{b}$ & + & n.t. & - & - & - & + \\
$\begin{array}{l}\text { Time scale } \\
\text { (days) }\end{array}$ & o $^{6}$ & 3 & 7 & 9 & 12 & 14 \\
\hline
\end{tabular}

PEFV, porcine endogenous retroviruses; PBMC, peripheral blood mononuclear cells; n.t., not tested; RT, reverse transcriptase.

aProviral DNA was detected by nested PCR using primers specific for PERV pol. Supernatants of infected cultures were pelleted and PERV RNA was detected in the pellets by RT-PCR.

Day of inoculation. $5 \times 10^{6}$ target cells in $10 \mathrm{ml}$ medium were inoculated by adding additional $10 \mathrm{ml}$ of PERV/293-containing supernatant (280 mU RT activity/ $\mathrm{ml}$. The virus used for inoculation had been produced by $1 \times 10^{7} 293 /$ PERV cells for 3 days. Mean \pm SD of triplicate measurement. 